Artigos

\title{
Entre ciência e docência? A experiência da USP para formar professores de Sociologia
}

Ana Paula Hey

Eduardo Carvalho Ferreira ${ }^{2}$

Maria Regina Cariello Moraes ${ }^{3}$

Resumo: Este artigo problematiza os desafios da formação de professores de Sociologia para o Ensino Médio, com base na experiência de implantação do Laboratório de Ensino de Sociologia na Universidade de São Paulo. Demonstrando interfaces entre a especificidade da formação universitária e a particularidade da docência no Ensino Médio, apresentam-se alguns elementos analíticos para a reflexão em torno desses processos formativos. Ademais, este trabalho visa contribuir para os estudos acerca da relação entre conhecimento científico e escolar, pesquisa e docência. Em especial, discutem-se as estratégias mobilizadas para a produção de materiais didáticos e recursos pedagógicos.

Palavras-Chave: Ensino de Sociologia; Formação de professores; Formação universitária e Ensino Médio; Habitus.

1 Departamento de Sociologia da Faculdade de Filosofia, Letras e Ciências Humanas - Universidade de São Paulo (USP) - São Paulo - Brasil - anaphey@uol.com.br

2 Departamento de Administração Escolar e Economia da Educação da Faculdade de Educação Universidade de São Paulo (USP) - São Paulo - Brasil - edu.ferreira@usp.br

3 Doutora em Sociologia pela Faculdade de Filosofia, Letras e Ciências Humanas - Universidade de São Paulo (USP) - São Paulo - Brasil - reginacariello@usp.br 


\title{
BETWEEN SCIENCE AND TEACHING? USP'S EXPERIENCE TO TRAIN SOCIOLOGY TEACHERS
}

\begin{abstract}
The article discusses the challenges for Sociology teachers training to high school, based on the experience in the implementation of Laboratory for Teaching of Sociology at the University of São Paulo. Demonstrating interfaces between the specificity of university education and the particularity of teaching in high school, we presente some analytical elements for the reflection around these formative processes. It aims to contribute to the studies on the relationship between scientific and school knowledge, research and teaching. In particular, we discuss the strategies mobilized in the practice for the production of didatic materials and pedagogical resources.
\end{abstract}

Keywords: Teaching of Sociology; Teachers training; University education and high school; Habitus.

Introdução: instituir o instituído

Desfazer o normal, há de ser uma norma. Manoel de Barros

Este artigo busca dialogar com os embates da formação de professores de Sociologia para o Ensino Médio com base na experiência singular desenvolvida em uma das instituições consagradas das Ciências Sociais no Brasil, a Universidade de São Paulo (USP). A criação do Laboratório de Ensino de Sociologia (LES), ligado ao Departamento de Sociologia da Faculdade de Filosofia, Letras e Ciências Humanas (FFLCH), constitui o mote para refletir acerca da formação de docentes para a escola básica, ao mesmo tempo em que possibilita inferir sobre a experiência formativa na universidade.

Os percalços que envolvem a formação de professores de Sociologia para a educação escolar remontam às origens da organização dos cursos de Ciências Sociais no Brasil, na década de 1920 (Cf. Martins, 2002; Neves, 2002; Meucci, 2015; Fazio, 2018; Almeida; Hey, 2018), tornando-se cíclicas as discussões sobre os limites e as possibilidades que abarcam tal tarefa. Contudo, desde a promulgação da última lei que rege a educação no país, a Lei de Diretrizes e Bases da Educação Nacional, em 1996, e especialmente a partir da Resolução do Conselho Nacional de Educação, em 2002, em que se estabeleceram novas orientações para a elaboração dos currículos de formação de professores da educação básica, o contexto converte-se favorável no campo das Ciências Sociais para se 
estabelecer mais diretamente questionamentos acerca da elaboração de propostas e programas formulados com ênfase na formação inicial de professores para a Educação Básica, no seio das mais reconhecidas instituições de formação de cientistas sociais no país.

Nessa direção, outro aspecto importante que impulsionou a reflexão sobre a formação de professores nos cursos de Ciências Sociais se deu em virtude da recente reintegração da disciplina escolar de Sociologia aos currículos do Ensino Médio. Assim, tanto a reforma curricular dos cursos de licenciatura como a "volta" da disciplina escolar resultaram em uma retomada significativa das reflexões sobre o lugar da formação de professores e suas novas implicações para os cursos de formação universitária (Cf. Moraes, 2013; Santos, 2014; Oliveira, 2016). Com isso, o desafio que se colocou às instituições foi justamente o de construir e propor modelos de formação orientados a correlacionar os conhecimentos e a práxis do campo científico com as práticas educativas exigidas pelas atuais configurações do sistema escolar.

Além disso, a prerrogativa da docência no Ensino Médio como possibilidade de mercado de trabalho para os cientistas sociais constitui fator imprescindível para estimular discussões de como conciliar a formação profissional em ambas dimensões: de pesquisador e docente. Como apontado por Liedke Filho (2006: 19), o ensino é uma das principais opções de trabalho dos cientistas sociais no país:

The main areas of work for sociologists are: teaching in elementary and high schools; teaching and research in public and private universities; research activities in non-university research centers; research and planning activities in public offices, as well as conducing social projects; research and consulting activities in the private sector, including private institutions of sociological research; and consulting activities for NGOs and social movements.

$\mathrm{Ou}$, ainda, a constatação exposta na nota da Sociedade Brasileira de Sociologia (SBS), publicada no boletim da International Sociological Association (ISA) sobre o ensino de Sociologia:

It is important to highlight a particular Working Group, the one focusing the issues related to the teaching of sociology in basic education. Thanks to the SBS, that champion the advocacy for sociology as a mandatory subject to be included in the basic education curriculum, since 2008, it became a legal requirement. According to law, issued by the federal government, in the three high school years there must be at least one hour per week of sociology teaching. Besides its importance to foster critical thought and to 
strength the notion of citizenship among the youth, it has opened a huge labour market for Brazilian sociologists. In 2014, there were nearly eight million students in high school in Brazil. This accounts for around 150 thousand classes needing a sociology teacher. This is why it is not surprising that so many Brazilian sociologists are interested in discussing how better teach the subject to their actual or potential students (ISA, 2015).

Esse momento impôs como necessidade aos cursos de Ciências Sociais a revisão de suas bases para a formação de professores para o Ensino Médio, obrigando-os a não só estabelecerem ajustes curriculares para se adequarem a novas demandas, mas também orientando-os a reconfigurar a relação entre ensino e pesquisa. Esta aproximação remete à redefinição dos papéis formativos do bacharelado e da licenciatura, uma vez que ambos tiveram seus lugares bastante hierarquizados no interior do campo acadêmico das Ciências Sociais. Mesmo que as novas diretrizes 4 não tenham resolvido a separação entre as duas formações (ensino e pesquisa) e, sobretudo, considerando o histórico desinteresse dos cientistas da área em relação à licenciatura, ainda assim parece que estamos avançando em relação à concepção de formar docentes que sejam também pesquisadores.

Tais circunstâncias impuseram o desafio da construção de iniciativas para promover a aproximação mais fecunda entre a formação inicial dos futuros professores e a realidade do sistema de ensino escolar e, principalmente, aumentaram a complexidade da reflexão sobre a natureza desse processo formativo, conferindo à temática um status particular no interior do campo disciplinar. Nesse sentido é que nos últimos anos temos observado a gênese de uma diversidade de projetos voltados para a inter-relação dessas duas esferas comumente distanciadas no interior dos cursos de Ciências Sociais e não no âmbito de formação das faculdades de Educação. Emerge, assim, a ideia de que a formação profissional para a docência não pode estar descolada da constituição do cientista social em sua origem.

Diante do cenário de expansão das licenciaturas e de eclosão de alternativas de formação no interior de cursos já consolidados é que este artigo intenciona se enquadrar. A partir de 2006, reformulações no interior da USP ensejaram a redistribuição de competências e autoridade no processo de formação do professor das várias áreas específicas, passando a retirar da Faculdade de Educação

4 A Resolução n. 01, de 18 de fevereiro de 2002, estabelece as Diretrizes Curriculares Nacionais para a Formação de Professores da Educação Básica, em nível superior, curso de licenciatura e de graduação plena e a Lei Federal n. 11.684/2008 institui a obrigatoriedade do ensino escolar de Sociologia. 
parte de atividades antes ali exclusivas. Assim, a FFLCH, polo de referência de constituição profissional dos cientistas sociais, dá início a um processo de ajuste curricular e organizacional para se adequar à divisão de alçadas.

A concretização das modificações advindas desse projeto se deu a partir de 2009, após o rearranjo institucional necessário, o que envolveu a contratação de professor, a criação de disciplinas e de outros espaços formativos. Destarte, apresentaremos na primeira seção do artigo a narrativa da prática de implantação da formação de professores de Sociologia para o ensino básico no interior da FFLCH, abarcando a exposição da concepção que norteia esta experiência. Em seguida, buscaremos realçar alguns aspectos sobre os contenciosos da formação de professores de Sociologia para o Ensino Médio.

\section{0 consagrado e o ilegítimo: novos espaços para formar professores de Sociologia}

A formação do professor de Sociologia para a escola de Ensino Médio, ou equivalente, considerando-se as variações de nomenclatura no sistema de ensino, não se constitui em experiência nova nos currículos brasileiros, como vimos anteriormente. $\mathrm{O}$ que tem se modificado nestes parcos últimos anos é a incorporação, mesmo que frágil e desigual nos diversos espaços institucionais, dessa discussão no interior dos cursos de formação do cientista social, deslocando-se do contexto habitual das faculdades de educação.

A experiência do Departamento de Sociologia da USP materializa esse deslocamento e as contradições correlatas entre mudanças que vão acontecendo sobrepostas a estruturas existentes e que não se modificam por força de lei ou reestruturação universitária, nacional ou local. $\mathrm{O}$ envolvimento de professores com as questões de ensino tende a ser pontual e pertencente a um número ínfimo de sujeitos. Mais ainda quando este ensino está voltado para a escola básica, universo afastado da pesquisa de excelência e das temáticas consagradas do campo disciplinar. Como corolário, tanto o processo de discussão de um novo formato de licenciatura em Ciências Sociais quanto sua implantação contaram com reduzida participação, o que reflete disputas em torno do que pode ser considerado legítimo e sobre a posição desses professores no campo acadêmico. Como o tema ensino não é um objeto de prestígio, consequentemente sua discussão deve pertencer a outro locus, não ao da ciência legítima por eles representada.

As alterações realizadas para contemplar a formação de professores em Ciências Sociais envolveram a redistribuição de 400 horas de práticas de estágio nas disciplinas obrigatórias da licenciatura. Assim, 300 horas permaneceram sob responsabilidade da Faculdade de Educação (Cf. FEUSP, 2014) e 100 
horas a cargo da FFLCH. Nessa última unidade foi criada a disciplina de Estágio Supervisionado para as Ciências Sociais, além da inclusão de Sociologia da Educação como obrigatória na grade da licenciatura. A FFLCH assumiu também a organização e o registro de 200 horas de Atividades Acadêmico-Científico-Culturais (AACC), tarefas extracurriculares exigidas para obtenção do diploma, além da constituição da disciplina optativa denominada Educação e sociedade: interfaces entre cultura e dominação, visando gerar uma área voltada à discussão educacional.

Nesse contexto, a coordenação do curso de licenciatura passou a ser incumbência dos professores do Departamento de Sociologia e ainda foi criado o $\mathrm{La}$ boratório de Ensino de Sociologia (LES), que passou a concentrar as atividades da licenciatura e a interface com seus alunos. $O$ estágio supervisionado tornou-se, então, o grande desafio a ser enfrentado, uma vez que a reestruturação proposta pela instituição não comportou a ampliação de fato do quadro docente, delegando a um professor a tarefa de organização e desenvolvimento integral da licenciatura.

A partir de questões relacionadas à feição marginal da área de licenciatura no interior dos jogos hierárquicos, expressa no desinteresse dos professores ali envolvidos, e do aspecto institucional - referente ao controle e à centralização na contratação de corpo docente -, em 2010, a coordenação do curso de licenciatura integrou o estágio supervisionado ao LES, visando ressignificar a experiência de estágio ao propor um modelo baseado na ideia de formação que aproximasse o licenciando com a realidade profissional docente, a partir do encontro entre teoria e prática in loco, mesmo que para tal os alunos não fossem às escolas. De novo um arranjo institucional vem à tona, uma vez que em um "acordo" com a Faculdade de Educação garantiu-se a inserção dos licenciandos no espaço escolar pela realização das disciplinas de estágio por ela oferecida, seja em atividades específicas de sala de aula seja nas atividades de organização e gestão escolar, compondo diversas modalidades que, juntas, totalizam 300 horas, conforme demonstrado na Tabela 1.

Tabela 1 - Distribuição de horas práticas de estágio entre FE e FFLCH

Disciplinas Obrigatórias da Faculdade de Educação

\begin{tabular}{|l|c|c|c|c|c|}
\hline $\mathbf{1}^{\mathbf{0}}$ Período Ideal & CA & CT & CH & CE & CP \\
\hline Atividades Acadêmico-Científico-Culturais (AACC) & 0 & 0 & 0 & & 40 \\
\hline Língua Brasileira de Sinais - EAD & 4 & 2 & 120 & & 30 \\
\hline Introdução aos Estudos da Educação (eletiva) & 4 & 0 & 60 & & 20 \\
\hline
\end{tabular}




\begin{tabular}{|l|c|c|c|c|c|}
\hline $\mathbf{2}^{\mathbf{0}}$ Período Ideal & & & & & \\
\hline Atividades Acadêmico-Científico-Culturais (AACC) & 0 & 0 & 0 & & 40 \\
\hline Psicologia da Educação (eletiva) & 4 & $\mathbf{1}$ & 90 & $\mathbf{3 0}$ & 20 \\
\hline Política e Organização da Educação Básica no Brasil & 4 & 2 & 120 & $\mathbf{6 0}$ & 20 \\
\hline $\mathbf{3}^{\mathbf{0}}$ Período Ideal & & & & & \\
\hline Atividades Acadêmico-Científico-Culturais (AACC) & 0 & 0 & 0 & & 40 \\
\hline Didática & 4 & $\mathbf{1}$ & 90 & $\mathbf{3 0}$ & 20 \\
\hline Metodologia do Ensino de Ciências Sociais I & 4 & 2 & 120 & $\mathbf{9 0}$ & \\
\hline $\mathbf{4}^{\mathbf{0}}$ Período Ideal & & & & & \\
\hline Atividades Acadêmico-Científico-Culturais (AACC) & 0 & 0 & 0 & & 40 \\
\hline Metodologia do Ensino de Ciências Sociais II & 4 & 2 & $\mathbf{1 2 0}$ & $\mathbf{9 0}$ & \\
\hline TOTAL CARGA HORÁRIA ESTÁGIO - FE & & & & $\mathbf{3 0 0}$ & \\
\hline
\end{tabular}

\section{Disciplinas Obrigatórias da FFLCH}

\begin{tabular}{|l|c|c|c|c|c|}
\hline $4^{\circ}$ Período Ideal & & & & & \\
\hline Atividades Acadêmico-Científico-Culturais (AACC) & 0 & 0 & 0 & & 40 \\
\hline Sociologia da Educação & 4 & 1 & 90 & & 20 \\
\hline Estágio Supervisionado para as Ciências Sociais & 4 & 2 & 120 & $\mathbf{1 0 0}$ & 30 \\
\hline TOTAL CARGA HORÁRIA ESTÁGIO - FFLCH & & & & $\mathbf{1 0 0}$ & \\
\hline
\end{tabular}

Fonte: Jupiterweb/USP. Legenda: Crédito Aula (CA); Crédito Trabalho (CT); Carga horária Total $(\mathrm{CH})$; Carga horária de Estágio (CE); Carga horária de Práticas como Componentes Curriculares (CP).

Visto que as atividades de estágio realizadas em escolas já compunham majoritariamente a carga horária, foi desenvolvido o projeto inovador do LES, ${ }^{5}$ espaço pensado para oferecer formação inicial qualificada para os futuros professores com base em sessões problematizadoras, discussões focais da realidade escolar e recuperação das vivências individuais e coletivas dos discentes. A intenção foi justamente constituir um espaço físico e, sobretudo, simbólico para hospedar o estágio e os licenciandos, atuando na criação da identidade da licenciatura em relação ao bacharelado. Vale lembrar que o plano simbólico não pode ser negligenciado quando estamos nos referindo a um jogo de legitimidade que envolve o consagrado academicamente e aquilo que é objeto de estigma, ou

5 De acordo com o Projeto Pedagógico das Licenciaturas (FEUSP, 2004), todos os "estágios supervisionados" deveriam ser feitos preferencialmente em escolas ou instituições correlatas, sendo seu projeto de trabalho previsto e elaborado por uma equipe de professores envolvidos com os variados cursos de licenciatura. Contudo, "casos excepcionais" poderiam ser aprovados pelas CoCs e a CAL/FE, desde que "com justificativa aceita pelas Comissões envolvidas", como ocorreu no estágio supervisionado em Ciências Sociais. 
melhor, entre a formação de disposições voltadas para o acadêmico como distinto e o escolar como ordinário. Assim, mesmo diante de uma conjuntura difícil para oferta do estágio supervisionado e da insuficiência de professores voltados a esta tarefa, as mudanças engendradas na USP em torno das licenciaturas proporcionaram o fomento de novos espaços de constituição e análise de questões específicas relacionadas ao trabalho docente e ao ensino escolar de Sociologia.

O LES passou a oferecer semestralmente a disciplina de estágio a um público bastante diversificado, composto por alunos matriculados na licenciatura em diversos momentos, desde os concluintes aos ingressantes no bacharelado, recém-egressos do bacharelado ou que o haviam abandonado há muito tempo, e um perfil peculiar de alunos que retornam para obter este diploma após ter cursado ou no momento de frequentar a pós-graduação (mestrado e doutorado), sendo estes cerca de $30 \%$ dos alunos por semestre. A dinâmica do laboratório busca se adequar a estes diferentes perfis, daí a opção pela realização de encontros e não o formato de aula para orientações conceituais e metodológicas, visando aproximar experiências singulares em uma atividade eminentemente socializadora. Tais encontros, além de discussões práticas e teóricas sobre as atividades em desenvolvimento, dirigem reflexões sobre as expectativas profissionais dos futuros professores, estabelecendo profícua troca de informações a respeito da mediação sobre o significado da docência em Sociologia e a educação escolar, problematizando vivências e inquietações por parte dos alunos.

Em termos operacionais, há o desenvolvimento de um programa de estágio que consiste na produção de um texto teórico de temática correspondente à área de Ciências Sociais, dirigido ao professor de Ensino Médio, e a criação de estratégias didáticas, envolvendo atividades direcionadas aos alunos. Deste modo, durante o semestre, com base em um tema curricular de livre escolha, cada aluno elabora um texto em formato de artigo científico, apoiado em revisão de literatura vigorosa sobre o assunto em pauta, e também produz um conjunto de atividades relacionadas à temática escolhida, denominado de repertório didático. Este deve conter propostas passíveis de serem desenvolvidas na íntegra ou recriadas pelos professores nas escolas.

O enfoque principal desse material produzido concentra-se na ampliação do repertório cultural do professor, tanto em relação ao conteúdo em si quanto em atividades inovadoras que ampliem sua visão no que se refere à abordagem do conteúdo, sendo priorizadas estratégias didáticas que utilizem filmes - comerciais, não comerciais, documentários, curtas-metragens, animações etc. -, fotografias, visitas virtuais e/ou presenciais a centros culturais e museus, charges, músicas e literatura de estilos diversos, peças teatrais, programas de TV aberta etc. 
A elaboração dos textos e repertórios visa, ainda, a qualidade e o rigor científico, mesmo que, algumas vezes, o resultado seja pouco aplicável em termos de número de aulas dedicado a um único tema, ou pela distância da realidade cotidiana que o recorte do tema possa apresentar. Desse modo, ao propor a criação desse tipo de material procura-se oferecer um apoio teórico e prático aos professores, servindo ele apenas como inspiração ou como uma composição com outros elementos, mas que descarte a elaboração de "apostilas". Objetivamente, os textos e as atividades do repertório didático podem ser manipulados pelos professores como fonte de estudos e como indicações de organização de aulas. Nas Tabelas 2 e 3 apresentam-se as áreas prevalecentes e os temas recorrentes dos alunos desenvolvidos entre 2010-2015.

Tabela 2 - Trabalhos produzidos pelos alunos por área

\begin{tabular}{lccc}
\hline & Área & Montante & $\%$ \\
\hline Antropologia & 31 & 18,5 \\
\hline Ciência Política & 12 & 7,15 \\
\hline Sociologia & 95 & 56,5 \\
\hline Outras & 30 & $\mathbf{1 7 , 8 5}$ \\
\hline Total & $\mathbf{1 6 8}$ & $\mathbf{1 0 0 , 0 0}$ \\
\hline
\end{tabular}

Fonte: Base de dados. LES/USP, 2015

Tabela 3 - Trabalhos produzidos pelos alunos por temas principais

\begin{tabular}{lcc}
\hline Temática & Montante & \% \\
\hline Ciência \& Tecnologia & 09 & 5,36 \\
\hline Conceitos Sociológicos Fundamentais & 25 & 14,88 \\
\hline Cultura e Diversidade & 30 & 17,86 \\
\hline Educação e Juventude & 09 & 5,36 \\
\hline Estudos Rurais e Urbanos & 09 & 5,36 \\
\hline Estudos sobre Política & 19 & 11,31 \\
\hline Gênero e Sexualidade & 07 & 4,17 \\
\hline Mídias e Indústria Cultural & 17 & 10,12 \\
\hline Questões raciais e Identidade Afrobrasileira & 08 & 4,76 \\
\hline Trabalho & 08 & 4,76 \\
\hline Violência & 09 & 5,36 \\
\hline Outras & 18 & 10,71 \\
\hline Total & $\mathbf{1 6 8}$ & $\mathbf{1 0 0 , 0 0}$ \\
\hline
\end{tabular}

Fonte: Base de dados. LES/USP, 2015 
Os textos e repertórios produzidos, depois de avaliados e com as devidas correções, são disponibilizados no site denominado USP ensina Sociologia (Disponível em: <www.ensinosociologia.fflch.usp.br>. Acesso em: 12 nov. 2018). $\mathrm{O}$ site funciona como propulsor da circulação da produção do laboratório, possibilitando certo grau de interação entre os alunos da licenciatura e o público escolar em geral, desde professores, alunos e outros interessados. A atualização de seus conteúdos é permanente, já que cada semestre novas elaborações temáticas são publicadas, além de oferecer outras informações para aprofundamento dos estudos dos professores, como indicações de bibliografia e filmes sobre diversos temas, links para outros laboratórios de ensino de Sociologia, para revistas acadêmicas e divulgação de eventos e matérias relevantes para a formação do licenciando. A seguir, apresentam-se nas Tabelas 4 e 5 as áreas predominantes dos conteúdos publicados, bem como os temas principais.

Tabela 4 - Trabalhos publicados no site por área

\begin{tabular}{lcc}
\hline Área & Montante & $\mathbf{\%}$ \\
\hline Antropologia & 10 & 18,87 \\
\hline Ciência Política & 04 & 7,55 \\
\hline Sociologia & 32 & 60,38 \\
\hline Outras & 07 & 13,20 \\
\hline Total & $\mathbf{5 3}$ & $\mathbf{1 0 0 , 0 0}$ \\
\hline
\end{tabular}

Fonte: Base de dados. LES/USP, 2015

Tabela 5 - Trabalhos publicados no site por incidência de tema

\begin{tabular}{lcc}
\hline Temática & Montante & $\mathbf{\%}$ \\
\hline Conceitos Sociológicos Fundamentais & 10 & 18,87 \\
\hline Cultura e Diversidade & 12 & 22,64 \\
\hline Educação e Juventude & 01 & 1,89 \\
\hline Estudos Rurais e Urbanos & 02 & 3,77 \\
\hline Estudos sobre Política & 07 & 13,21 \\
\hline Gênero e Sexualidade & 06 & 11,32 \\
\hline Mídias e Indústria Cultural & 04 & 7,55 \\
\hline Questões raciais e Identidade Afrobrasileira & 04 & 7,55 \\
\hline Trabalho & 03 & 5,66 \\
\hline Violência & 04 & 7,55 \\
\hline Total & $\mathbf{5 3}$ & $\mathbf{1 0 0 , 0 0}$ \\
\hline
\end{tabular}

Fonte: Base de dados. LES/USP, 2015. 
Ainda que somente parte dos textos e repertórios didáticos produzidos no LES seja selecionada para publicação, a atividade proposta no programa de estágio supervisionado proporciona o contato, às vezes inédito, dos graduandos com a autoria de determinado tema de sua preferência, instigando novos interesses e projetos para a continuidade dos estudos. Nesse sentido, a conjugação da produção do texto teórico à construção de um repertório didático desenvolvido durante o estágio representa uma espécie de trabalho de conclusão de curso da licenciatura, no qual se encontram e complementam-se os papéis de pesquisador e de professor.

Por esta razão, o modelo das atividades praticadas no LES foca a integração das diversas facetas da função de cientista social: a pesquisa, a objetividade e a expressão de ideias (texto teórico); a translação da teoria em prática de ensino (o repertório didático); a elaboração crítica de um tema (sessões problematizadoras); a cooperação com outros professores em formação (as discussões focais); a interface com as escolas (o site). Outro aspecto relevante refere-se à atividade de extensão, uma vez que por meio do site e dos materiais ali disponibilizados pode ocorrer a conexão com dinâmicas escolares distribuídas em todo o território nacional, uma espécie de contribuição tácita à sociedade. ${ }^{6}$

A opção por tal modelo de formação permite trabalhar diferentes estratégias didáticas junto aos graduandos em Ciências Sociais em vários níveis, de maneira a desenvolver o habitus de professor amalgamando-se ao habitus de cientista construído durante a formação no bacharelado e, sobretudo, reforçando seu estabelecimento. No referencial bourdieusiano utilizado aqui, ${ }^{7}$ habitus pode ser definido como uma matriz de percepções, apreciações e ações assimilada do grupo de origem e incorporada de modo não consciente. É um sistema de disposições que envolve a classificação do mundo e que indica formas de ação, pensamento e conduta dos indivíduos, constituindo predisposições mentais, julgamentos e apreciações da realidade acumulados pelo agente em sua trajetória de vida e lapidados em suas experiências, em especial, as de educação e aquelas provenientes da ligação com novos grupos sociais. Assim, para

6 A partir do site, outras instituições, como as Secretarias de Educação, a UNIVESP TV/Fundação Padre Anchieta, universidades e escolas públicas e particulares e professores passaram a entrar em contato com o LES, buscando informações, dando depoimentos do uso dos materiais produzidos ou solicitando apoio pedagógico.

7 A teoria da prática desenvolvida por Bourdieu é a base da discussão do habitus, pois traz à tona os limites da determinação da estrutura sobre o indivíduo e do livre desenvolvimento intencional de objetivos pelos sujeitos. O desafio reside justamente em entender a prática aliando habitus e capital a um determinado campo social. Na sociologia contemporânea, a noção tem sido utilizada quase se descolando dessa implicação dada pelo autor (cf. Grenfell, 2018, p. 75-78). 
Bourdieu (1983), também cada campo profissional desenvolve determinado habitus, uma vez que abarca um processo educacional realizado por especialistas e que abrange a formação de "capacidades treinadas e propensões estruturadas para pensar, sentir e agir de modo determinados, que então as guiam nas suas repostas criativas aos constrangimentos e solicitação do seu meio social existente" (Wacquant, 2017: 214).

Isto é, o aluno em formação traz para as reuniões de estágio incorporações de ações práticas, concepções e percepções inscritas em sua forma de agir e nas escolhas realizadas, instalando em estado prático um tipo de capital culturals específico, o científico, mas também outro relativo à cultura geral. Estes tipos de capital interferem na sua forma de elaborar as atividades exigidas, pois nota-se que durante o desenvolvimento do estágio cada licenciando estabelece um movimento próprio nas interfaces entre a sua origem social, a formação inicial em Ciências Sociais, as visões de mundo e as concepções educacionais. Paira sobre cada texto e repertório didático elaborado uma relação particular entre teoria e prática, entre o que deve ou não ser a atuação do cientista social como educador.

As experiências no estágio extrapolam os limites de uma produção teórica ou didática. Antes, coadunam-se às disposições incorporadas como habitusg no bacharelado, resultando em uma multiplicidade de propostas de trabalho que refletem os entendimentos sobre a natureza da função docente. $O$ impacto que a proposta em pauta enseja para a formação profissional do aluno talvez não possa ser expressa em dados quantitativos, posto que cada qual constrói um habitus particular em relação à diversidade de dispositivos existentes no campo acadêmico das Ciências Sociais. O licenciando acaba combinando em sua trajetória uma variedade de referenciais sobre o que é ciência, o que é ser professor ou aluno, qual o papel da escola, dentre outras práticas. Tornar-se professor, então, refere-se à operacionalização de um rol de conhecimentos e estratégias típicos dos ambientes científicos formadores aliados aos apreendidos em outros espaços de socialização.

Parte da preocupação formativa reside em fazer com que os alunos entrem em contato com uma dimensão importante da docência, que é a seleção de

8 Uma explicação mais aprofundada do conceito de habitus na teoria sociológica de Pierre Bourdieu e de sua relação intrínseca com a noção de acumulação de capital cultural pode ser encontrada em Wacquant (2007; 2017). Confira também Bourdieu (1983, 1998, 2008).

9 Acreditamos que o uso adequado da noção implica sua prova empírica, todavia aqui a utilizamos tão simplesmente para ressaltar o efeito da socialização acadêmica da USP, que gera um modo de relacionamento com o conhecimento científico pautando, em grande medida, a representação do que seja formar-se professor. 
referências e a organização de peças teóricas e didáticas para a elaboração de aulas. Mas outra diz respeito a fazê-los tomar posição e se tornarem autônomos na sua capacidade de fazer escolhas teóricas e metodológicas. Isso representa alçá-los como agentes do processo formativo, estimulando o desenvolvimento da consciência crítica e do rigor científico para a composição de seu habitus profissional. Durante o estágio, os licenciandos são "obrigados" a mobilizar essas diferentes maneiras de pensar e agir, transferindo para a elaboração de sua prática a confluência das disposições de estudante, de pesquisador e de professor.

Por outro lado, embora as atividades de estágio supervisionado tenham a virtude de oferecer experiência na função docente, que não tiveram foco específico durante o bacharelado, contraditoriamente reproduzem a hierarquia entre a valorização da formação para a pesquisa em relação ao magistério no Ensino Médio. Exemplo disso reflete-se na produção discente, cujos licenciandos experientes em pesquisa acadêmica e especialistas em algum tema, em termos tendenciais, apresentam melhor desempenho do que aqueles desprovidos de tal aparato. Parcela da explicação para esse fato encontra-se na desenvoltura escrita e de comunicação adquiridas por alunos que elaboraram ou estão realizando pesquisas de iniciação científica, mestrado ou doutorado, devido à prática frequente de elaboração de relatórios, artigos e exposição oral em congressos e afins.

Outro aspecto refere-se ao grau de heterogeneidade do perfil discente, ${ }^{10} \mathrm{cujo}$ acesso a experiências diversificadas, que extrapolam a realização de disciplinas formais, exigiriam maior atenção da universidade. De certa forma, a proposta do LES tenta preencher esta lacuna, pois busca incentivar a prática de produção de textos com foco específico, exercitando o desenvolvimento da exposição objetiva e do olhar sociológico para questões determinadas, habilidades necessárias na pesquisa e nas aulas de Sociologia no Ensino Médio.

A despeito disso, com a organização das atividades de estágio no LES, tornou-se possível garantir a inter-relação constante entre as atividades da licenciatura com o conjunto do curso de bacharelado, algo que não acontecia anteriormente. Pode-se dizer que esta conjuntura tem trazido o reconhecimento progressivo da licenciatura por parte do público discente, incrementando as discussões sobre a formação de professores para a educação básica no curso de Ciências Sociais da USP.

10 Diversidade já exposta em trabalhos como de Comin e Barbosa (2011), demonstrando que 44,6\% dos alunos de graduação trabalham e $40 \%$ deles têm idade superior a 25 anos. 
Cabe registrar que durante o primeiro ano de funcionamento do laboratório, em 2010, o interesse pela licenciatura e pela nova disciplina de estágio foi insignificante, considerando que se registrou a desistência de dois terços dos alunos matriculados no primeiro semestre. Entretanto, de lá para cá, sobretudo com a implantação do site, em 2011, gradualmente a procura por matrículas aumentou e a evasão diminuiu bastante, como podemos ver na Tabela 6, a seguir:

Tabela 6 - Matriculados e concluintes por ano

\begin{tabular}{cccc}
\hline Ano & Matriculados & Concluintes & \% \\
\hline 2010 & 18 & 07 & 38,8 \\
\hline 2011 & 40 & 35 & 87,5 \\
\hline 2012 & 48 & 35 & 70,8 \\
\hline 2013 & 45 & 34 & 75,5 \\
\hline 2014 & 53 & 40 & 75,4 \\
\hline $2015^{*}$ & 20 & 17 & 85,0 \\
\hline Total & $\mathbf{2 2 0}$ & $\mathbf{1 6 8}$ & \\
\hline
\end{tabular}

Fonte: Base de dados. LES/USP, 2015

* Somente até o primeiro semestre de 2015. A disciplina oferece 20 vagas por semestre devido ao espaço físico do laboratório e à natureza do trabalho oferecido.

Vários fatores poderiam ser elencados para o aumento da demanda. Aqui destacamos a reintegração da disciplina de Sociologia no Ensino Médio, abrindo um flanco necessário em termos de mercado de trabalho, mas também os bons resultados pedagógicos apresentados pela disciplina de estágio e pela divulgação do LES, o que não significa o descarte de aprimoramentos ou de que essa fórmula sirva para outras realidades acadêmicas. A experiência aqui relatada constitui-se em uma possibilidade elaborada para atender à formação do cientista social de uma instituição com total ênfase em pesquisa e que precisou voltar sua atenção para a formação do professor de Sociologia.

Há, com clareza, necessidade de inovações futuras, mas que precisam tornar-se objeto da conjugação entre condições objetivas (subsídio financeiro e recursos humanos disponíveis) e instauração da cultura de ensino no projeto individual dos docentes ali atuantes (envolvimento de maior número de professores com o ensino de Sociologia, projetos de pesquisa relacionados ao ensino etc.). Como exemplo dessas possibilidades pode-se citar, entre outras ideias, a possibilidade de interatividade virtual com professores da rede pública, a criação 
de cursos temáticos de curta duração para alunos e professores e a elaboração de projetos interdisciplinares pelos alunos de licenciatura para serem desenvolvidos em escolas.

A existência de um espaço privilegiado como o LES cumpre uma tarefa cara ao curso de Ciências Sociais da USP, que durante muitos anos vinha secundarizando tal atribuição. As atividades ali realizadas servem não só como subsídio para a produção de material didático para os professores do Ensino Médio, mas também como reflexão acerca de modelos formativos das licenciaturas em Ciências Sociais, posto que visam incluir na agenda do curso a preocupação com uma espécie de iniciação científica à docência, articulando a formação inicial dos alunos com as questões abordadas no ensino escolar de Sociologia.

A formação de professores de Sociologia configura-se como área incipiente de estudos no Brasil, embora o interesse pelo tema venha aumentado nos últimos anos. Segundo levantamento feito por Handfas \& Maçaira (2014: 52), "a formação do professor tem sido tratada em sua relação com questões do ensino. No entanto, só encontramos uma dissertação que se dedicou à relação entre bacharelado e licenciatura e seus impactos na formação do professor de sociologia”. A conhecida intermitência da obrigatoriedade da disciplina no currículo escolar durante o último século foi apenas um dos fatores que contribuíram para desestimular o campo das Ciências Sociais a se envolver efetivamente na formação para a docência. Ademais, a relevância de tal tarefa constitui-se em motivos de descrença para grande parte dos acadêmicos, ocasionando o afastamento de tais discussões ou tornando-as conjunturais.

Particularmente no caso da FFLCH da USP, o movimento inconstante de aproximação e afastamento das questões de ensino marca sua origem. $\mathrm{O}$ antigo Instituto de Educação, responsável pela formação de professores, é incorporado à instituição quando ela é fundada, em 1934, e transformado em Seção de Educação da Faculdade de Filosofia, em 1938, até se constituir em Faculdade de Educação (Cf. Hey; Catani, 2006), desvinculando os estudos para a docência do científico e profissional. As controvérsias sobre a competência de tal tarefa também se concentravam em poucos protagonistas, eles mesmos objetos de polêmica, como visto no caso de Fernando de Azevedo, que assume a cadeira de Sociologia Educacional na Faculdade de Filosofia em um contexto bastante particular:

A entrada de Azevedo na cadeira de Sociologia Educacional em 1938 se dá após o fechamento pelo governador Adhemar de Barros do IEUSP (Instituto de Educação da Universidade de São Paulo) e a garantia, por parte do 
governador, de que todos os professores catedráticos do Instituto seriam realocados para cadeiras em outras faculdades da Universidade. Tal entrada causa insatisfação por parte de Paul Arbousse Bastide que não pensa que a nova diretriz da Universidade deva aceitar membros da Escola Normal (ARBOUSSE-BASTIDE, 1981, p.84) e críticas dos adversários políticos de Azevedo, que não reconhecem seus méritos acadêmicos. (Tomei, 2015: 11).

Os embates no interior da Faculdade de Filosofia prosseguiram entre a formação científica, a profissional e a formação de professores para a escola básica, motivados por questões de natureza bem diversas, entre elas a entrada de setores médios ou em ascensão nos quadros universitários e em cursos de humanidades, reservando a setores de elite os cursos "nobres" (Cf. Hey; Catani, 2006). O imaginário aí construído e a prática social equivalente colocam em último plano a preocupação com o ensino baseado na exigência de formação específica, bem como separando, de certa forma, as esferas da ciência, da profissão (liberal) e da docência escolar. Assim exposto por Moraes (2003: 14):

Desde então, aprofundando-se a partir de 1969 com a Reforma Universitária, que desintegrou de vez a antiga Faculdade de Filosofia, Ciências e Letras em várias faculdades, institutos e escolas (Instituto de Física, Instituto de Química, Instituto de Matemática e Estatística, Escola de Comunicações e Artes, Faculdade de Filosofia, Letras e Ciências Humanas) e criou a Faculdade de Educação, há uma relação difícil entre o bacharelado e a licenciatura, constituindo cursos com objetivos diversos: um forma pesquisadores ou técnicos e o outro forma professores.

É certo que de lá para cá ocorreram mudanças institucionais, em que destacamos a mais recente no tocante à reforma das licenciaturas em todas as unidades da USP, fato que culminou com a elaboração do Programa de Formação de Professores, em 2004 (Cf. USP, 2004). A partir daí, como mencionado anteriormente, o cenário da formação de professores de Sociologia se altera em termos de concepção curricular, envolvimento de quadro docente e percepção por parte dos alunos, passando a ser uma tarefa dividida entre a FFLCH e a Faculdade de Educação.

Apesar da conjuntura adversa - formar professores como um setor pouco valorizado pela academia e de oferta instável no Ensino Médio - a proposta que vem sendo desenvolvida pelo LES baseia-se em uma concepção do sistema de ensino escolar e dos fenômenos educacionais como objetos de caráter científico e que demandam formação prática especializada. Assim, a tentativa é 
concretizar a formação docente equilibrando os conhecimentos específicos das Ciências Sociais, as noções didáticas e pedagógicas e as metodologias de pesquisa e ensino. $\mathrm{O}$ conjunto deste trabalho de articulação entre pesquisa e ensino baseado na produção de recursos teóricos e repertórios didáticos tem gerado mudanças tácitas significativas para o desenvolvimento da formação docente no interior do curso de Ciências Sociais da USP.

\section{0 cenário de formação de professores de Sociologia para o Ensino Médio: otimis- mo da vontade e pessimismo da inteligência?}

A célebre frase do escritor e musicólogo francês Roman Rolland (1866-1944) nos serve de mote para expressar o cenário da formação de professores de Sociologia no Brasil, em que, muitas vezes, a necessidade de acreditar em mudanças suplanta os números com os quais nos deparamos. Essa contradição inerente vem acompanhando a produção na área, como veremos a seguir.

Ao analisar os estudos sobre a situação dos professores de Sociologia no Brasil, depreende-se que o quadro é bastante complexo. Segundo Moraes (2003), a campanha pela obrigatoriedade da disciplina escolar de Sociologia "novamente põe em contato os profissionais da área" e também faz ressurgir "o clamor por programas e materiais didáticos", prevalecendo o entendimento de que a reconquista do espaço da disciplina no currículo acarreta necessariamente no resgate de uma característica essencial que foi deixada de lado pelas Ciências Sociais brasileiras: a aproximação com a educação básica.

Nos últimos dez anos, mesmo que as Ciências Sociais brasileiras tenham continuado concentradas nos termos fixados pela qualificação e produtividade da pesquisa científica, no seu interior aportam-se muitas experiências voltadas para pensar o "problema" do ensino. Tal contexto tem impulsionado uma nova fase para as licenciaturas, emergindo novos referenciais para a formação de professores, a produção de materiais didáticos e paradidáticos, novos espaços dentro dos cursos e departamentos, novas formas de interface com escolas, professores e alunos do Ensino Médio, além de melhorar a formação inicial e abrir um campo de pesquisas para os cientistas sociais.

Apesar dessa guinada, um ponto de inflexão nos é apresentado pela pesquisa feita por Silva e Vicente (2014), que indica uma situação emblemática ao revelar o levantamento nada animador sobre a formação inicial dos professores que estão à frente da disciplina. Tal constatação se dá pela análise dos dados fornecidos pelo censo escolar realizado pelo Instituto Nacional de Estudos e Pesquisas Educacionais Anísio Teixeira (INEP), em 2012, ao demonstrar que somente 
uma pequena porcentagem de professores possui a formação específica que deveria pautar o ensino na área, como exposto na Tabela 7:

Tabela 7 - Principais formações específicas dos professores de Sociologia no Ensino Médio

\begin{tabular}{lc}
\hline Título de Licenciatura / outros & $\%$ \\
Ciências Sociais & 17,92 \\
\hline História & 17,14 \\
\hline Pedagogia & 12,10 \\
\hline Filosofia & 11,78 \\
Geografia & 8,09 \\
\hline Letras & 3,96 \\
Outras licenciaturas & 4,02 \\
\hline Bacharelado em Ciências Sociais & 2,68 \\
\hline Bacharelado em Pedagogia & 2,44 \\
\hline Bacharelado em Direito & 0,68 \\
\hline
\end{tabular}

Fonte: INEP, 2012 apud Silva; Vicente, 2014.

Tal configuração é assim compreendida por Silva e Vicente (2014):

[...] ainda que a maior proporção de professores seja de licenciados em Ciências Sociais $(17,92 \%)$, a soma de professores formados nos cursos de Ciências Sociais (bacharelado e licenciatura) é de apenas $20 \%$. Um ponto positivo para o ensino de Sociologia é que a grande concentração de professores que lecionam possuem cursos de licenciatura e também fazem parte da área de Ciências Humanas. De tal modo, além de possuírem nos seus cursos de formação uma preparação didática, possuem como referência as Ciências Humanas (Silva; Vicente, 2014: 75).

Essas informações revelam um cenário bastante defasado de professores formados em Ciências Sociais e atuantes no Ensino Médio, ocultando ainda que esses números gerais agregam fortes discrepâncias regionais, relativas à distribuição entre os estados e entre as cidades de maior ou menor porte populacional e econômico. Segundo as notas estatísticas do censo escolar de 2017 (MEC, 2018: 19), persiste ainda grande inadequação da formação docente para a disciplina Sociologia no Ensino Médio, pois, "das disciplinas de Sociologia declaradas nas turmas de ensino médio, apenas $27,1 \%$ são ministradas por professores com a formação mais adequada", o que, nesse quesito, a coloca como o pior 
resultado dentre as demais disciplinas escolares, cuja média é 70\%. Leia-se, no gráfico, que o grupo 1 refere-se a professores com licenciatura na disciplina que lecionam, o grupo 2 de professores com bacharelado na área da disciplina, mas sem licenciatura, o grupo 3 comporta professores com licenciatura, mas não na disciplina que lecionam, o grupo 4 diz respeito a professores sem licenciatura ou bacharelado na área que lecionam e, por fim, o grupo 5 refere-se a docentes sem curso superior completo.

Gráfico 1 - Adequação da Formação Docente do ensino médio por disciplina - 2017

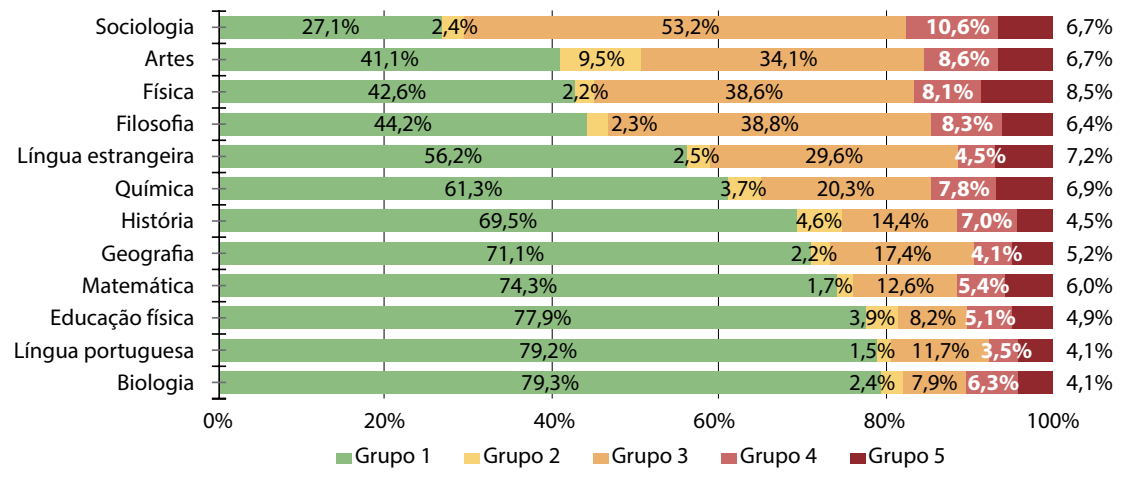

Fonte: Censo Escolar INEP/MEC (2018)

Outros autores, entre eles Handfas (2013), apontam um cenário de mudança, afirmando que há um movimento em curso no campo das Ciências Sociais que parece ter estimulado e aumentado a procura pela licenciatura. Uma das causas seria profissional, visto que se configura como uma nova alternativa no mercado de trabalho para os formados, um nicho ainda não saturado, pois a inclusão da disciplina no currículo é recente e a falta de professores licenciados é grande.

A esse respeito, desde 2005, o Programa de Educação Tutorial (PET) tem realizado levantamento junto aos alunos de graduação em Ciências Sociais da USP, revelando que a intenção dos ingressantes de realizar a licenciatura tem crescido exponencialmente. $\mathrm{O}$ fato é que o processo de adequação do curso para englobar atividades de formação de professores de Sociologia ainda está em andamento, como vimos na seção anterior, mas as experimentações têm corroborado a maior aproximação com as discussões de ensino de Sociologia, tanto para o conjunto de professores quanto para os discentes.

Em paralelo a esse crescimento da demanda por licenciatura, impulsionado nos últimos anos após o retorno ao currículo, tende-se a aumentar também os fóruns de debate acerca da formação do professor de Sociologia, o que já vem 
ocorrendo em importantes congressos nacionais da área, como o Encontro Nacional sobre o Ensino de Sociologia na Educação Básica (ENESEB) e o GT Ensino de Sociologia da Sociedade Brasileira de Sociologia (SBS). ${ }^{11}$

Muitas discussões, entretanto, continuam em aberto, entre elas a que diz respeito ao perfil profissional desejado e se haveria adequação dos cursos de graduação para oferecer essa formação, como apontaram Tânia Silva et al. (2009) ao analisarem a situação da licenciatura na Universidade Federal de Sergipe. Uma das indagações recorrentes, ainda, refere-se à compatibilidade entre a ênfase da graduação na formação para a pesquisa especializada em nível de pós-graduação e a formação para o ensino generalista voltado para a escola. Inclusive a possibilidade de inter-relação entre os papéis de pesquisador e de professor é evocada, em que emerge a defesa de uma atitude mais prática da Sociologia no Ensino Médio, um afastamento do gabinete por assim dizer.

Handfas e Teixeira (2007) apontam como questão crucial para pensar o ensino de Sociologia o cuidado que se deve ter no esforço de transposição de conteúdos, visando não minar o caráter científico da Sociologia na intenção de aproximação com a realidade dos alunos do Ensino Médio. Isto é, à licenciatura compete a tarefa de destacar novas formas de se ensinar Ciências Sociais na Educação Básica, demonstrando, na prática, sua preocupação com a variedade de intenções em relação aos desafios impostos pela didatização dos conhecimentos científicos. A clássica discussão dos fundamentos mesmos das Ciências Sociais é colocada em cheque, como exposto por Bernard Lahire:

Eis uma série de questões que giram em torno da utilidade e da inutilidade efetivas ou desejadas da Sociologia, com as quais os pesquisadores são sempre inevitavelmente confrontados. Visto que ela tem sua atenção mais frequentemente voltada para sua própria sociedade e para os fatos que são contemporâneos ou que têm repercussões no mundo contemporâneo; visto que ela preenche, por vezes, funções críticas, e que seus resultados são geralmente legíveis pelos mesmos "objetos" de suas pesquisas, a Sociologia é uma ciência comumente forçada a passar tanto tempo a explicar e a justificar seus procedimentos e sua existência quanto a entregar os resultados de suas análises. A singular situação das Ciências Sociais é, portanto, particularmente desconfortável. Porque não somente é exaustivo ter de responder,

11 Conferir o trabalho de Oliveira (2016: 67), que assim qualifica o GT: "Trata-se de uma comunidade de pesquisadores cada vez mais ativa, que se articula a partir de outros espaços institucionais, e que se volta para um objeto que tem ganhado maior destaque nas discussões acadêmicas, dada sua relevância científica e social". Estão engajados no GT muitos daqueles considerados as principais referências nesse debate, não à toa mostra-se recorrente a citação a um grupo restrito de autores que discutem Ensino de Sociologia, e que atuam amiúde neste grupo. 
continuamente, a questão "para que serve?", como mais desconfortável ainda é o fato de que a resposta "isso não serve pra nada" está frequentemente na mente daquele que faz tal pergunta (Lahire, 2014: 47).

Para as autoras supracitadas (2007: 137), as propostas que defendem "processos educacionais impulsionados fundamentalmente pela experiência imediata ou pela prática cotidiana de seus agentes" podem resultar em retrocesso para o ensino de Sociologia, no sentido de separar a prática da teoria, quando o que se pretende é aproximá-las. Na mesma direção, Vargas (2013) tece críticas às práticas de ensino que utilizam os fenômenos cotidianos dos alunos como estímulo pedagógico, mas que não conseguem apresentar opções de interpretação apoiadas nos referenciais teóricos do campo disciplinar.

Somente professores com uma sólida formação são capazes de sugerir materiais, referências e interpretações fundamentadas no arsenal teórico metodológico das ciências sociais, capazes de superar uma interpretação puramente subjetiva e vaga dos fenômenos discutidos. Essas práticas reforçam, de certa maneira, a ideia de que qualquer um é capaz de trabalhar os conteúdos da sociologia, já que os temas de que tratam concernem a todos e todos têm opiniões mais ou menos formadas a respeito deles. O desafio do trabalho do professor de sociologia é exatamente o oposto, de construir junto com os alunos uma interpretação que não seja apenas opinião (...) A grande dificuldade do trabalho do professor de sociologia é exatamente o de transitar entre esses diversos discursos e níveis de conhecimento, de saber reconhecê-los, de identificar suas características, diferenças e distintos alcances na apreensão da realidade (Vargas, 2013: 09).

Isso não quer dizer que as práticas de ensino de Sociologia devam ser pautadas apenas por transmissão de conteúdos teóricos. Seria apropriado encontrar um equilíbrio entre teoria e prática sem se deixar seduzir pelo pragmatismo nem pela erudição exacerbada. Ainda como ressalta Vargas (2013: 10), os “objetivos pragmáticos conspiram contra o ensino da Sociologia que raramente será considerado prático, sustentando-se muito mais numa preparação mais geral para a 'cidadania' e para uma convivência social crítica”. É importante ter clareza, como assinalou o autor, que o desenvolvimento do olhar sociológico apurado é um projeto social e político mais abrangente que a formação dos alunos do Ensino Médio, referindo-se à construção dos agentes nas relações sociais.

Outros autores identificaram a desvalorização da função de professor em relação ao papel de pesquisador no interior das Ciências Sociais e os obstáculos 
para a formação de pesquisadores que sejam também professores, principalmente em cursos que separam a licenciatura do bacharelado. Um ponto importante para discussão diz respeito à falta de prestígio acadêmico desse novo nicho de trabalho para sociólogos, que, no ethos preponderante entre os cientistas sociais, é visto como lugar ocupado por alunos despreparados para o enfrentamento da abstração teórica e mais afeitos à razão prática. Como observamos no caso da USP, também Silva et al. (2009) apontaram a divisão existente no interior dos cursos:

Em geral, há em muitos casos uma hierarquia velada nos cursos de Ciências Sociais e/ou Sociologia atribuindo à licenciatura um status menor em relação ao bacharelado, essa tem sido uma queixa comum feita pelos estudantes e professores de várias instituições do país nos inúmeros fóruns e encontros realizados onde a temática foi colocada. (...) Outra questão a ser discutida diz respeito à valorização das duas formações no âmbito de muitas instituições de ensino superior. Parece haver em algumas instituições de ensino uma valorização menor da licenciatura em relação ao bacharelado que passa a ser visto tanto pelo corpo docente como pelos alunos como uma formação melhor. A licenciatura seria "o caminho natural" dos alunos considerados mais "fracos" e que não estariam aptos a enfrentar a monografia de conclusão de curso. Ou seja, por aqueles que "não tem perfil acadêmico", "vocação para pesquisadores”, portanto para a carreira acadêmica (Silva et al., 2009: 08).

Em pesquisa realizada com docentes de cursos superiores de Ciências Sociais acerca da formação de professores para o Ensino Médio, Silva et al. (2009) demonstram que eles não se sentem responsáveis pela Licenciatura, delegando essa responsabilidade para as disciplinas de prática de ensino ministradas em departamentos ou faculdades de Educação, sendo mais marcante tal característica entre os docentes das áreas de Antropologia e Ciência Política. Nesse item, também constatamos, como demonstrado anteriormente, situação similar com a experiência da Licenciatura da USP, em dois aspectos: a inserção de atividades de formação de professores no espaço da graduação centra-se na área de Sociologia e as escolhas das temáticas dos alunos para a realização das atividades didáticas também se concentram nesse domínio.

Cabe ressaltar que a falta de prestígio social da profissão de professor no Brasil, de maneira geral, poderia ser apontada como um dos fatores culturais que contribuem negativamente para desqualificar o ensino de Sociologia no âmbito acadêmico, reforçando a distinção entre os que pensam e os que "se limitam a ensinar" (Handfas, 2013: 390). Com essa visão bastante arraigada, a 
questão que merece relevo, aqui, refere-se a como não tornar essa ladainha um fator de imobilidade para inovações que precisam ser realizadas no interior dos cursos de formação acadêmica.

Se hierarquias foram geradas entre pesquisa-ensino-extensão, se fatores relativos à estruturação da carreira acadêmica reforçam a predominância da pesquisa acadêmica publicada em relação à formação profissional, se critérios avaliativos desqualificam a função de ensino, estes elementos constituem-se em dados objetivos que devem ser considerados. Nessa circunstância, a formação de professores não pode ficar refém da espera de uma transformação estrutural, ainda mais ao se considerar o crescimento da demanda por professores qualificados e as necessidades postas pelo mercado de trabalho. Assim é que entendemos que a experiência que ora analisamos possa contribuir para os estudos da área.

\section{Considerações finais}

[Os alunos] não se contentavam em recitar uma sequência de palavras, já não era somente uma questão de guardar na memória, era na inteligência da língua, da língua de outro, o pensamento de um outro. Eles não recitavam Emílio, eles restituíam o raciocínio de Rousseau (...) é o vaticínio imprecatório de Jean-Jacques que se exprime pela sua boca!

Daniel Pennac, Diário de Escola, 2008.

A perspectiva aqui desenvolvida como reflexão de uma prática que vem se desenvolvendo comporta a epistemologia de como entendemos e de como nos posicionamos no processo relativo ao ensino de uma disciplina como a Sociologia. Sujeita a embates internos ao campo disciplinar, que na configuração atual desfavorece as questões de ensino, também é atingida no espaço da educação básica ao ser desprovida de importância diante das consideradas "disciplinas soberanas", como Português e Matemática, ou de suas parceiras das Ciências Humanas, como História e Geografia. Agrega-se a isso a resistência da população em geral, devido às questões ideológicas inerentes aos estudos sociológicos, como assinala Vargas (2013), ou ainda à própria construção midiática associada a setores sociais conservadores, que atacam as disciplinas de cunho crítico considerando-as nefastas à formação dos jovens, expressa nos movimentos Escola sem Partido, Universidade sem Partido, entre outros.

A interface buscada entre o habitus desenvolvido no curso de graduação, o ethos que envolve a organização do currículo e a prática dos docentes e os 
princípios simbólicos relativos à hierarquia do campo disciplinar comandaram a estruturação da experiência. Como previsto inicialmente, as mudanças ocorridas com as ações na Licenciatura refletiram, sobretudo, no conjunto do curso de Ciências Sociais, colaborando para a construção da legitimidade da área no seio das preocupações consagradas.

Outro aspecto relevante que se busca evidenciar diz respeito ao desenvolvimento da interface entre conhecimento científico e transmissão escolar, no interior de uma instituição voltada à pesquisa acadêmica de alto nível, como possibilidade de inversão do papel do aluno passivo, que está recebendo/ absorvendo conhecimento, para o papel do aluno produtor de um tipo de conhecimento diferente, qual seja, aquele relativo ao ensino e aprendizado escolar. Pressupondo o professor como aquele que deve mediar a interface entre dois universos tão próximos e tão distantes, o desafio reside em levar o licenciando a entender que a tarefa de aprender e o procedimento de ensinar são práticas que exigem exercícios, constituindo-se em processos de internalização de um olhar sociológico.

Tal olhar demanda conhecimento profundo e familiaridade com os objetos e as questões da área, porém esta construção não pode ser a mesma exigida no contexto da educação básica. Acreditamos tratar-se de levar os alunos em formação rumo a um caminho de autoria e autonomia, cuja finalidade é criar modelos próprios de didatização que expressem a incorporação - mesmo que por vezes simplificada - das teorias, objetos e métodos das Ciências Sociais e a consequente transposição no ensino escolar. Mesmo que tal empreitada não seja muito fácil de concretizar, posto que a experiência nos revele dezenas de meios distintos para se conseguir produtos intelectuais que deem conta de tal dinâmica, o escopo consiste em transformar "abstrações" em objetos de ensino, realizando uma ação prática para revelá-los "ensináveis, ou seja, acessíveis aos professores e seus alunos" (Chatel; Groose, 2014: 108).

Assim, o trabalho no LES passou a ter um objetivo bastante pragmático de elaboração de material didático, uma novidade também para o aluno, que precisa pensar em algo definido e aplicável, rompendo muitas vezes com a lógica abstrata da ciência, dominante no seu processo de formação acadêmica. Contudo, essa talvez seja uma possibilidade de enfrentar o desafio de junção da teoria com a prática, que tanto se professa, sem se afastar das bases epistemológicas que norteiam o campo científico, experiência com a qual esperamos contribuir para a formação de qualidade dos professores de Sociologia. 


\section{Referências}

ALMEIDA, Ana Maria F. de; HEY, Ana Paula. Sociologia da Educação: olhares sobre um campo em ascensão. In: Miceli, Sergio e Martins, Carlos Benedito (Orgs.). Sociologia brasileira hoje II. São Paulo, Ateliê Editorial, 2018, pp. 253-310.

BOURDIEU, Pierre. Sociologia (Org. ORTIZ, Renato; Coord. FERNANDES, Florestan). São Paulo, Ática, 1983.

BOURDIEU, Pierre. Escritos de educação. (Org. NOGUEIRA, Maria Alice; CATANI, Afrânio). Petrópolis, Vozes, 1998.

BOURDIEU, Pierre. A distinção: crítica social do julgamento. São Paulo, Ed. USP; Porto Alegre, Zouk, 2008 [1979].

BRASIL. Ministério da Educação e do Desporto. Lei de Diretrizes e Bases da Educação Nacional. Brasília, DF, MEC, 1996.

BRASIL. Resolução n. o1, de 18 de fevereiro de 2002. CNE, Brasília, DF, 2002.

CHATEL, Elisabeth.; GROOSE, Gérard. O Ensino Sociológico nos Estabelecimentos de Ensino Médio: entre problemas sociais e sociologia acadêmica. Educação \& Realidade. Porto Alegre, v. 39, n. 1, jan-mar 2014, pp. 99-111.

COMIN, Álvaro.; BARBOSA, Rogério. Trabalhar para estudar: sobre a pertinência da noção de transição escola-trabalho no Brasil. Novos estudos - CEBRAP. São Paulo, n. 91, novembro 2011, pp. 75-95.

FACULDADE DE EDUCAÇÃO - USP. Projeto Pedagógico das Licenciaturas, 2014. HANDFAS, Anita. O estado da arte do ensino de sociologia na educação básica: um levantamento preliminar da produção acadêmica. Inter-legere, Natal, n. 13, jul-dez 2013, pp. 386-400.

FAZIO, Luísa Helena M. de. Questões acerca da Sociologia da Educação no Brasil - Uma entrevista com Ana Paula Hey. Revista Eventos Pedagógicos. Sinop, MT, v. 9, n.3, nov-dez 2018, pp. 1280-1304.

HANDFAS, Anita; MAÇAIRA, Julia Polessa. O estado da arte da produção científica sobre o ensino de sociologia na educação básica. BIB. São Paulo, n. $74,2^{\circ}$ semestre de 2012, publicada em julho de 2014, pp. 43-59.

HANDFAS, Anita.; TEIXEIRA, Rosana Câmara. A prática de ensino como rito de passagem e o ensino de Sociologia nas escolas de nível médio. Mediações. Londrina, v. 12, n. 1, jan-jun 2007, pp. 131-142.

HEY, Ana Paula.; CATANI, Afrânio Mendes. A USP e a formação de quadros dirigentes. In: MOROSINI, Marília (Org.). A universidade no Brasil: concepções e modelos. Brasília, INEP, 2006, pp. 295-312. 
ISA - International Sociology Association. 17th Brazilian Congress of Sociology, Newsletter July 2015. Disponível em: <https://www.isa-sociology.org/uploads/ files/17th_brazilian_cs_2015.pdf>. Acesso em: 14 nov. 2018.

LAHIRE, Bernard. Viver e interpretar o mundo social: para que serve o ensino da Sociologia? Revista de Ciências Sociais. Fortaleza, v. 45, n. 1, jan-jun 2014, pp. 45-61. LIEDKE FILHO, Enno D. Brazilian Sociology: contemporary epistemologicaltheoretical and institutional trends. Sociologias. Porto Alegre, v. 1, Selected Edition, 2006. Disponível em: <http://socialsciences.scielo.org/pdf/s_soc/vinse/scs_ao2.pdf>. Acesso em: 14 nov. 2018.

MARTINS, Carlos Benedito. Estudos sociológicos sobre educação no Brasil (comentário crítico). In: MICELI, Sergio (Org.). O que ler na ciência social brasileira (19702002) - v. 4. São Paulo, Sumaré/Anpocs, 2002, pp. 439-455.

MEUCCI, Simone. Sociologia na educação básica no Brasil: um balanço da experiência remota e recente. Ciências Sociais Unisinos. São Leopoldo, v. 51, n. 3, set-dez 2015, pp. 251-260.

MINISTÉRIO DA EDUCAÇÃO. Censo Escolar 2017: notas estatísticas. Brasília, INEP/ MEC, 2018.

MORAES, Amaury Cesar. Licenciatura em Ciências Sociais e ensino de Sociologia: entre o balanço e o relato. Tempo Social. São Paulo, v. 15, n. 1, abril 2003, pp. 5-20.

NEVES, Clarissa Eckert Baeta. Estudos sociológicos sobre educação no Brasil. In: MICELI, Sergio (Org.). O que ler na ciência social brasileira (1970-2002). v. 4, São Paulo, Sumaré/Anpocs, 2002.

OLIVEIRA, Amurabi. O ensino de sociologia na educação básica brasileira: uma análise da produção do GT ensino de sociologia na SBS. Revista Teoria e Cultura. Juiz de Fora, v. 11, n. 1, jan-jun 2016, pp. 55-70.

PENNAC, Daniel. Diário de escola. São Paulo, Rocco, 2008 (240).

SANTOS, Mario Bispo dos. O PIBID na área de Ciências Sociais: condições epistemológicas e perspectivas sociológicas. Revista Brasileira de Sociologia. Rio de Janeiro, v. 2, n. 3, 2014, pp. 55-79.

SILVA, Ileisi.; FIORELLI, Luciana. O ensino das ciências sociais/Sociologia no Brasil: histórico e perspectivas. In: MORAES, Amaury C. de (Org.). Coleção explorando o ensino de Sociologia. Brasília, MEC, 2010, pp. 23-31.

SILVA, Ileisi.; VICENTE, Daniel Vitor. Quadro nacional dos docentes de sociologia no ensino médio: desafios da formação docente entre textos, dados e contextos. $O$ público e o privado. Fortaleza, n. 24, jul-dez 2014, pp. 69-8o.

SILVA, Tania Elias M. et al. Sociólogo-professor: novos desafios para a formação profissional. Anais do XIV Congresso Brasileiro de Sociologia. GTo7 - Ensino de Sociologia. Rio de Janeiro, 2009. 
TOMEI, Francesco. Fernando de Azevedo, durkheimiano brasileiro? Relatório de pesquisa de iniciação científica desenvolvido junto à FFLCH/USP. FAPESP, 10/01/2015.

UNIVERSIDADE DE SÃO PAULO. Programa de Formação de Professores. PróReitoria de Graduação da USP, Comissão Permanente dos Cursos de Licenciatura, São Paulo, USP, 2004.

Laboratório de Ensino de Sociologia (LES). Usp ensina Sociologia. Disponível em: <www.ensinosociologia.fflch.usp.br>. Acesso em: 14 nov. 2018.

VARGAS, Francisco Eduardo Beckenkamp. O ensino de sociologia: dilemas de uma disciplina em busca de reconhecimento. In: SCHWARZ, Vera Lúcia Dos Santos. (Org.). Educação básica: Um debate teórico sobre o ensino da sociologia. Porto Alegre, UFRGS, $1^{\text {a }}$ edição, 2013.

WACQUANT, Loïc. Esclarecer o habitus (Dossiê Pierre Bourdieu). Educação \& Linguagem. São Bernardo do Campo, SP, ano 10, n. 16, jul-dez 2007, pp. 63-71.

Habitus. In: CATANI, Afranio Mendes.; NOGUEIRA, Maria Alice.; HEY, Ana Paula.; MEDEIROS, Cristina. (Orgs.). Vocabulário Bourdieu. Belo Horizonte, Autêntica, 2017, (400).

Recebido em 20/03/2017

Aprovado em 19/02/2018

\section{Como citar este artigo:}

HEY, Ana Paula; FERREIRA, Eduardo Carvalho e MORAES, Maria Regina Cariello. Entre ciência e docência? A experiência da USP para formar professores de Sociologia. Contemporânea - Revista de Sociologia da UFSCar, v. 8, n. 2, jul.- dez. 2018, pp. 635-661. 